\title{
Kajian Desain Perhiasan Tulola Jewelry Dengan Inspirasi Budaya Bali
}

\author{
Rika Nugraha \\ Program Studi Kriya Tekstil dan Mode, Fakultas Industri Kreatif \\ Universitas Telkom
}

\begin{abstract}
The potential of jewelry Indonesia in the international high-end segment is Tulola Jewelry that resemble the culture of the archipelago through the inspiration of Balinese culture, thus successfully penetrate the world market. The purpose of this paper is first, Tulola jewelry to produce products worldwide. Secondly, Tulola jewelry inspired by the culture of Bali. Third, how to design visualization of Tulola Jewelry

The method used is the qualitative approach to the study of iconography as identification, description and interpretation of icons based on the attributes of the marker. The end result of this research collaboration Tulola Jewelry is a traditional Indonesian jewelry with a modern twist, excellence Tulola Design Jewelry as jewelry Indonesia has a distinctive feature compared with jewelry from other countries. A blend of modern technology and traditional Balinese motifs make jewelry look artistic.
\end{abstract}

Keywords : Bali, Tulola, Ikonography

\section{PENDAHULUAN}

Indonesia kaya akan berbagai budaya dan kesenian, salah satunya dalam bentuk perhiasan. Perempuan adalah pengguna perhiasan yang paling utama dalam berbagai kesempatan, dengan menggunakan material yang cukup variatif. Pergeseran penggunaan perhiasan bertema tradisional dan etnik yang dikenakan oleh perempuan muda sangat terlihat, disebabkan banyaknya desainer-desainer muda menciptakan jenis perhiasan mengikuti perkembangan zaman. Proses pembuatan dan pengembangan perhiasan, disesuaikan dengan fenomena yang tengah berlaku di masyarakat. Perkembangan perhiasan dari masa ke masa menggambarkan karakter dan budaya yang berbeda dari tiap-tiap jamannya. Desain perhiasan yang inovatif memiliki dasar kreatifitas serta terinspirasi berdasarkan pengamatan budaya salah satunya adalah Tulola Jewelry.

Konsep desain perhiasan Tulola Jewelry terinspirasi dari budaya Bali, dibuat dengan menambahkan sentuhan modern kaya tradisi sehingga dapat dikenakan oleh perempuan masa kini. Tulola Jewelry memiliki desain unik, proses pengerjaan perhiasan dilakukan 
melalui tangan para seniman Jawa dan Bali. Tradisi budaya Bali diterjemahkan melalui desain pada Tulola Jewely dengan mengambil bentuk gamelan musik khas Bali, bentuk Pura Besakih serta kondisi geografis Bali. Desain Tulola Jewelry telah mendapatkan pengakuan warga negara diluar Indonesia mengenai keindahan perhiasan khas Indonesia.

\section{Rumusan Masalah}

Dari uraian latar belakang tersebut di atas, maka dapatlah dirumuskan beberapa pokok permasalahan sebagai berikut :

- Apa saja pendukung keberhasilan Tulola Jewelry sehingga menghasilkan produk yang mendunia?

- Mengapa Tulola Jewelry mengambil inspirasi dari budaya Bali ?

- Bagaimana visualisasi desain perhiasan dari Tulola Jewelry?

\section{LANDASAN TEORI}

\section{Kerajinan}

Dalam Ensiklopedi Indonesia disebutkan kerajinan tangan adalah jenis kesenian yang menghasilkan atau memproduksi berbagai jenis barang hiasan yang terbuat dari kayu, rotan, tulang, gading, porselin, perak dan sebagainya (Van Hoeve, 1983 : 1745).

\section{Perhiasan}

Perhiasan berkaitkan dengan fashion, karena benda-benda yang dikenakan dianggap dapat mendukung penampilan seseorang. Studi perhiasan sebagai bagian dari fashion tidak saja berbicara bentuk material saja, namun peran dan makna perhiasan dalam tindakan sosial. Perhiasan sebagai ciri khas dari suatu fenomena tertentu, dapat menjadi popular dan dianggap sebagai sebuah tren di masyarakat. Menurut Charlotte Mankey \& Phyllis Tortora (2003).

Terdapat 2 jenis perhiasan :

1. Mulia/ murni, Real Jewelry

a. Logam Emas, Perak, Platina

b. Batu mulia : Berlian, Intan, Ruby, Zamrud, Zafir

c. Batu $1 / 2$ mulia : Jade, Giok, Mutiara, Topaz, Coral, Agat

2. Costume Jewelry

a. Logam tiruan / Imitasi

b. Bahan alam : Kayu, Rotan, Bambu, Biji,

c. Akar Bahar, Gading, Tanduk, Bulu, Kerang.

Terdapat Bentuk Perhiasan:

1. Bentuk Klasik: Cunduk, Suweng, Blong (Jogja), Binggel (Madura )

2. Bentuk Kontemporer / Modern.

Terdapat Macam Perhiasan:

1. Anklet (gelang kaki )

2. Armlet (gelang tangan- kecil )

3. Necklace (Kalung)

4. Bracelet (Gelang)

5. Brooch (Bros)

6. Buckle (Gesper)

7. Earing (Anting)

8. Fibula (Peniti)

9. Pendant (Liontin) 
10. Pomander (Liontin Bukaan)

11. Ring (Cincin)

\section{Desain}

Secara etimologis kata "disain" diduga berasal dari kata designo (Itali) yang artinya gambar. Kata ini diberi makna baru dalam bahasa Inggris di abad ke 17, yang dipergunakan untuk membentuk School of Design tahun 1836. Makna baru tersebut dalam praktik kerap semakna dengan kata craft (keterampilan adiluhung), sebagai seni berketerampilan tinggi (art and craft). Pengertian lain Desain adalah salah satu manifestasi kebudayaan yang berwujud dan merupakan produk nilai-nilai untuk suatu kurun waktu tertentu (Widagdo dalam Sachari, $2005:$ 7).

Pengertian desain dapat dilihat dari berbagai sudut pandang dan konteksnya. Desain juga mengandung pengertian sebagai suatu kreasi seniman untuk memenuhi kebutuhan tertentu dengan cara tertentu pula. (Gropius dalam Sachari, 2005 : 5). Pada awal perkembangannya, istilah "disain" tersebut masih berbaur dengan "seni" dan "kriya", namun ketika seni modern mulai memantapkan diri dalam wacana ekspresi murni, justru "disain" memantapkan diri pada aspek fungsi dan industri (Sachari, $2005:$ 3).

\section{Segmentasi Pasar}

Menurut laporan market brief produk perhiasan dari Indonesian Trade Promo Center (Direktorat Jendral Pengembangan Ekspor
Nasional, Hal 5-6, 2013), Segmentasi Pasar terbagi atas:

1. Remaja ( Low-End Consumer )

Konsumen remaja umumnya menyenangi perhiasan dengan harga terjangkau.

2. Kaum Muda (Mid-End Consumer) Kalangan muda umumnya usia 2030 tahun perhiasan bukan lagi sebagai aksesoris namun sebagai pelengkap kebutuhan penting. Body Jewelry sepeti jam tangan, kalung dan cincin merupakan perhiasan favorit di kalangan muda.

3. Dewasa (High-End Consumer)

Kalangan ini dapat dikategorikan pada usia 30 tahun ke atas dan didominasi oleh masyarakat menengah atas yang menyukai designer branded goods.

\section{METODE PENELITIAN}

Menjawab permasalahan yang dikemukakan dalam penelitian ini, kajian yang digunakan ialah studi Ikonografi. Ikonografi adalah kajian tentang identifikasi, deskripsi dan interpretasi ikon berdasarkan atribut yang menjadi penandanya. Jenis penelitian ini adalah kualitatif, yaitu jenis penelitian yang temuantemuannya diperoleh melalui prosedur analisis non-matematis (Strauss, $2003: 4-$ 5). Dalam penelitian ini penalaran yang digunakan adalah induktif, yang didasarkan pada kajian fakta-fakta atau gejala khusus untuk disimpulkan sebagai gejala yang bersifat generalisasi empiris (Tanudirjo, 1988:34). Dengan 
demikian, sifat penelitian ini ialah deskriptif. Pada hakekatnya,bertujuan untuk memberikan gambaran suatu fakta atau gejala tertentu yang diperoleh dalam penelitian. Dengan demikian penelitian ini mengutamakan kajian data, yang dikaitkan dengan kerangka ruang, waktu, dan bentuk (Tanudirjo, 1988:34). Kajian desain perhiasan ini mengambil budaya Bali antara lain berupa ikon gapura Bali, Bunga Padma, Gamelan, Gong, Barong Bali serta terdapat pelengkap ikon lainnya dengan inspirasi Nusantara.

\section{HASIL DAN ANALISA}

Tulola Jewelry merupakan kolaborasi produk Sri Luce Rusna dan artis Happy Salma, untuk mengembangkan brand perhiasan Tulola. Happy berkeyakinan tradisi dan kemewahan itu mampu menembus pasar premium dan berkembang menjadi besar bila dikerjakan dengan serius. Menemukan visi yang sama, keduanya merintis dan mengembangkan hingga produk Tulola telah mendunia

Tulola jewelry mengusung konsep heritage, menjadikan produk perhiasan ini berbeda di pasaran, seperti mendesain kembali anting model subeng yang sudah tak banyak digunakan orang. Sumber inspirasi Tulola datang dari mana saja, mulai dari lagu sampai sejarah bangsa, budaya dan alam Indonesia.
Terdapat koleksi Juwita Malam yang terinspirasi dari lagu karya Ismail Marzuki. Koleksi ini menggambarkan kecantikan dan keanggunan misterius wanita Indonesia. Kejelian Tulola soal branding berhasil meletakkan produknya di pasar high end. Mereka membuka flagship store tak hanya di Bali, bahkan di New York, untuk membuka pasar internasional. Dengan langkah ini, tak hanya figur publik yang mulai mengenal Tulola, tapi juga media asing yang berdatangan untuk meliput produk mereka. W Magazine USA memasukkan gold cuff dari Tulola sebagai Most Wanted List 2012. Selain itu, penyanyi rock Courtney Love juga menggunakan gladiator cuff dan temple cuff Tulola di sampul NME Magazine.

Terinspirasi gaya perhiasan Indonesia kuno dengan penekanan detail, desain Tulola dikerjakan secara hand made. Perhiasan yang dibuat dikerjakan oleh tangan sehingga eksklusif dengan berpegang pada filosofi Tulola. Perhiasan diproduksi melalui pengerjaan cukup rumit, beberapa produk Tulola hanya bisa dikerjakan oleh tangan-tangan tertentu oleh pembuat perhiasan / master ( pengrajin perak).

Satu produk Tulola waktu pengerjaannya hingga satu bulan dan tidak memproduksi perhiasan secara massal. Tulola menggunakan bahan baku perhiasan yang terbaik, mulai dari emas murni sampai berlian. Kerumitan dalam pembuatan, penggunaan bahan 
berkualitas, hingga waktu pengerjaan yang cukup lama membuat beberapa desain Tulola hanya tersedia dalam limited edition. Oleh karena itu Tulola memilih untuk memasuki pasar high end yang tidak menuntut kapasitas produksi yang tinggi dan daya beli pasarnya cukup tinggi. Selain itu, di kalangan konsumen premium, perhiasan ini juga menjadi benda koleksi yang bernilai tinggi. Terbukti, perhiasan eksklusif koleksi Tulola yang harganya bisa mencapai Rp 20 jutaan dapat terjual di pasaran.

Menembus pasar high end sangatlah tidak mudah, apabila produk tersebut mampu mengambil hati kaum jetset hingga di mancanegara. Kelebihan segmentasi pasar high end yang tahan gempuran krisis membuat banyak orang meliriknya. Tapi, bermain di segmentasi pasar ini, harga menjadi perkara nomor dua. Produk yang istimewa dan keterampilan mengambil hati konsumen menjadi yang utama.

Tulola dapat bersaing dan diterima pasar disebabkan memiliki desain berkonsep matang diwujudkan dalam sebuah teknik pengerjaan yang sangat teliti dan dikerjakan oleh master-master terbaik. Bahkan, untuk menjaga kualitas dan menghasilkan produk yang terbaik, Tulola tidak ragu untuk berani berinvestasi bahan dan alat-alat khusus. Investasi berupa alat-alat khusus dari Italia, mendatangkan langsung teknisi untuk melatih pegawai Tulola Jewelry.
Produk terbaru Tulola juga menggunakan berlian yang pemotongannya khusus dilakukan di Bangkok. Mengadakan pameran untuk memperkenalkan produknya kepada pasar menjadi langkah awal yang dilakukan oleh Tulola ketika mengembangkan usaha ini. Tulola Jewelry termasuk kepada Real Jewelry dikarenakan mereka menggunakan bahan utama yang terbuat dari Logam mulia/ murni, Emas, Perak, Platina, Batu mulia seperti: Berlian, Intan, Ruby, Zamrud, Zafir. Adapun bentuk perhiasan dari Tulola memadumadankan bentuk klasik: Cunduk, Suweng/Subeng dan bentuk kontemporer / modern.

\section{Kajian Ikonografi Tulola Jewelry}

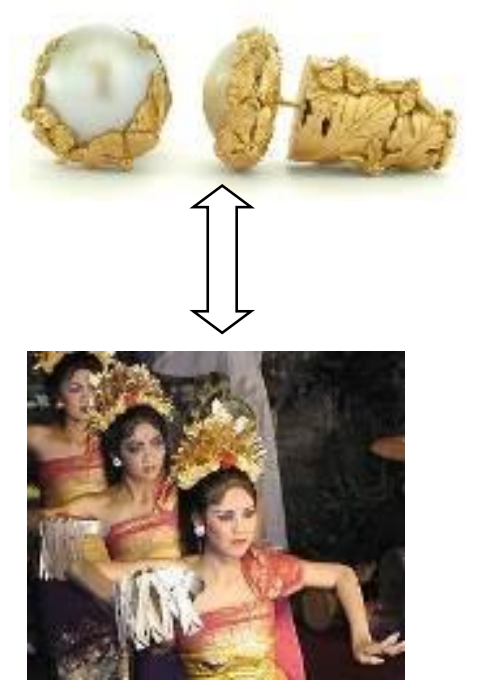

Gambar 1. Tolula Jewelry Design - Subeng (Sumber : www.shoptulola.com, 2015) 


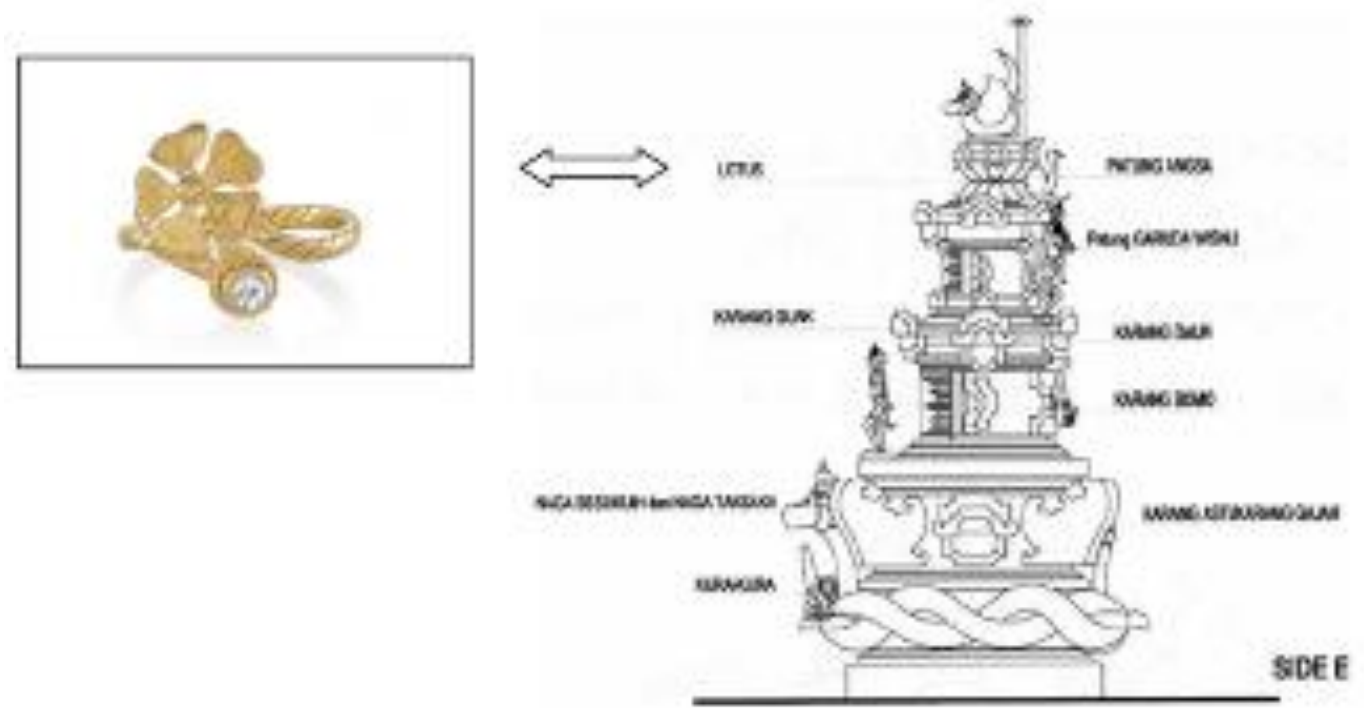

Gambar 2. Tolula Jewelry Design - Padma Ring (Sumber: www.shoptulola.com, 2015)

Subeng digunakan sebagai pelengkap perhiasan dalam tari pendet sebagai tarian ritual sakral odalan di pura yang disebut mamandet atau mendet. Prosesi mendet berlangsung setelah pendeta mengumandangkan puja mantranya dan seusai pementasan topeng sidakarya- teater sakral yang secara filosofis melegitimasi upacara keagamaan. Hampir setiap pura besar hingga kecil di Bali disertai dengan aktivitas mamendet. Pada beberapa pura besar seperti Pura Besakih yang terletak di kaki Gunung Agung itu biasanya secara khusus menampilkan ritus mamendet dengan tari Baris Pendet. Tari ini dibawakan secara berpasangan atau secara masal oleh kaum pria dengan membawakan perlengkapan sesajen dan bunga.
Merupakan bunga lambang kesucian agama Hindu, lotus dalam bahasa Sansekerta disebut 'Padma'. Tumbuhan yang dianggap suci oleh masyarakat Bali, bunga teratai (padma) dijadikan simbol alam semesta stana Hyang Widhi yang sebenarnya. Dalam Lontar "Dasa Nama Bunga" disebut, bunga teratai adalah rajanya bunga (Raja Kesuma) karena hidup di tiga alam akarnya menancap di lumpur, batangnya di air, sedangkan daun dan bunganya di atas air (udara). Karenanya, bunga ini adalah simbol Tri Loka atau Tri Bhuwana Stana Hyang Widhi Wasa dan bunga daunnya yang berlapis-lapis sebagai perlambang dari sembilan arah penjuru mata angin alam semesta (I Ketut Wiana, 2004). 

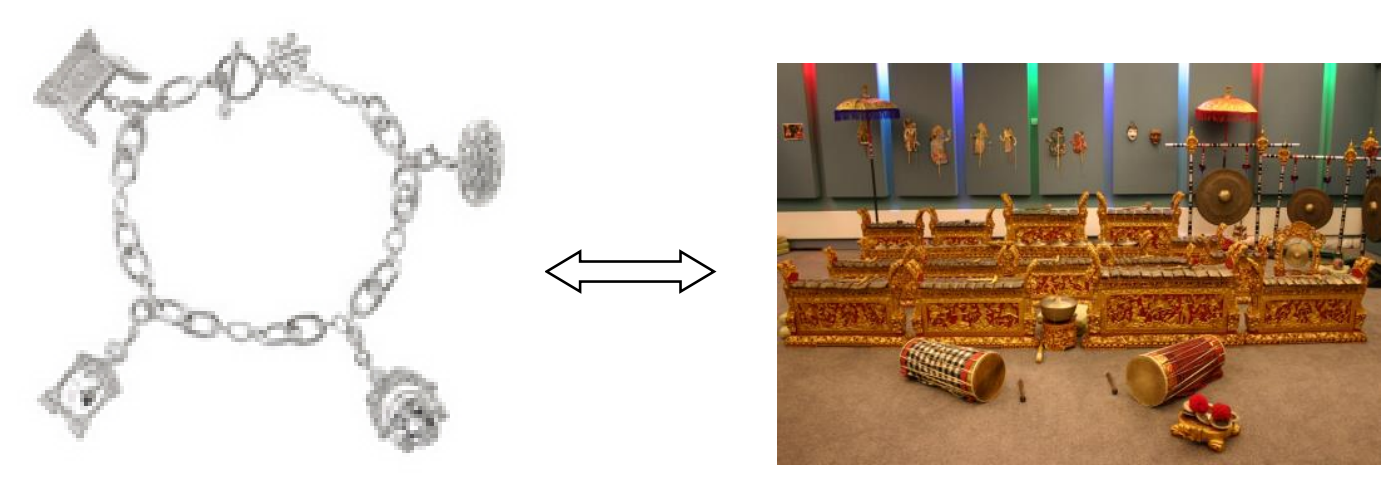

Gambar 3. Tolula Jewelry Design - Stories From Bali : Gamelan Set (Sumber.www.shoptulola.com, 2015)
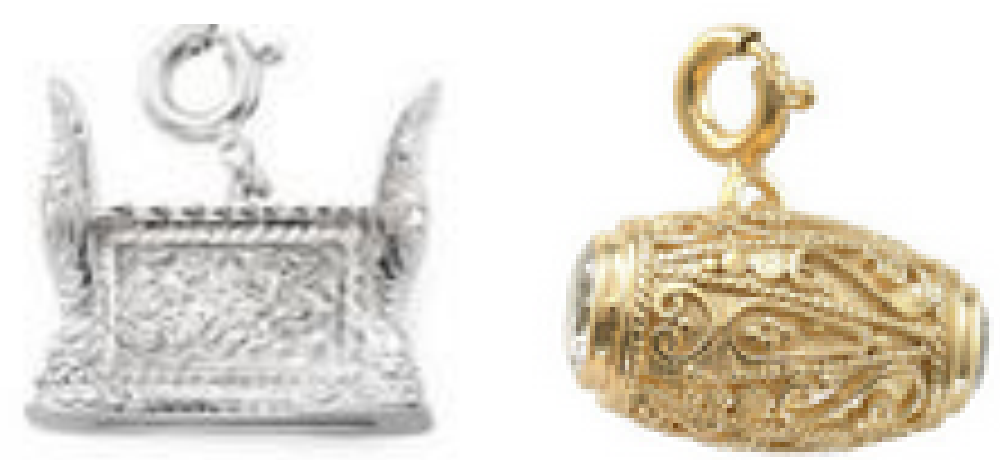

Gambar 4. Tolula Jewelry Design Stories From Bali : Gamelan Charm \& Kendang Drum Sumber.www.shoptulola.com, 2015)

Gamelan Bali merupakan alat musik khas Bali sebagai gamelan pengiring ritual adatadat Bali. Gamelan selama ini identik dengan kebudayaan Jawa. Namun, di Pulau Dewata, Bali, ternyata alat musik ini juga menjadi bagian dalam kesenian khas pulau yang terkenal dengan keindahannya ini. Gamelan atau di Bali dikenal dengan sebutan gambelan biasa digunakan dalam acara-acara prosesi ritual adat seperti upacara kematian yang kita kenal dengan tradisi ngaben. Sementara untuk upacara manusia yadnya digunakan gender dan untuk upacara di pura biasanya digunakan gong gede.
Burung garuda yang akhirnya menjadi Garuda Pancasila bagi bangsa Indonesia tersebut ditemukan dalam sejarah mitologi Hindu dan Buddha. Di dalam Mitologi Buddha, burung garuda ini digambarkan sebagai burung pemakan daging yang hebat dan memiliki kemampuan berorganisasi secara sosial. Dalam mitologi Hindu, burung garuda yang nantinya lebih dikenal sebagai Garuda Pancasila ini digambarkan sebagai setengah manusia dan setengah burung yang sering digunakan oleh Dewa Wisnu sebagai kendaraannya. Burung garuda juga menjadi raja dari 


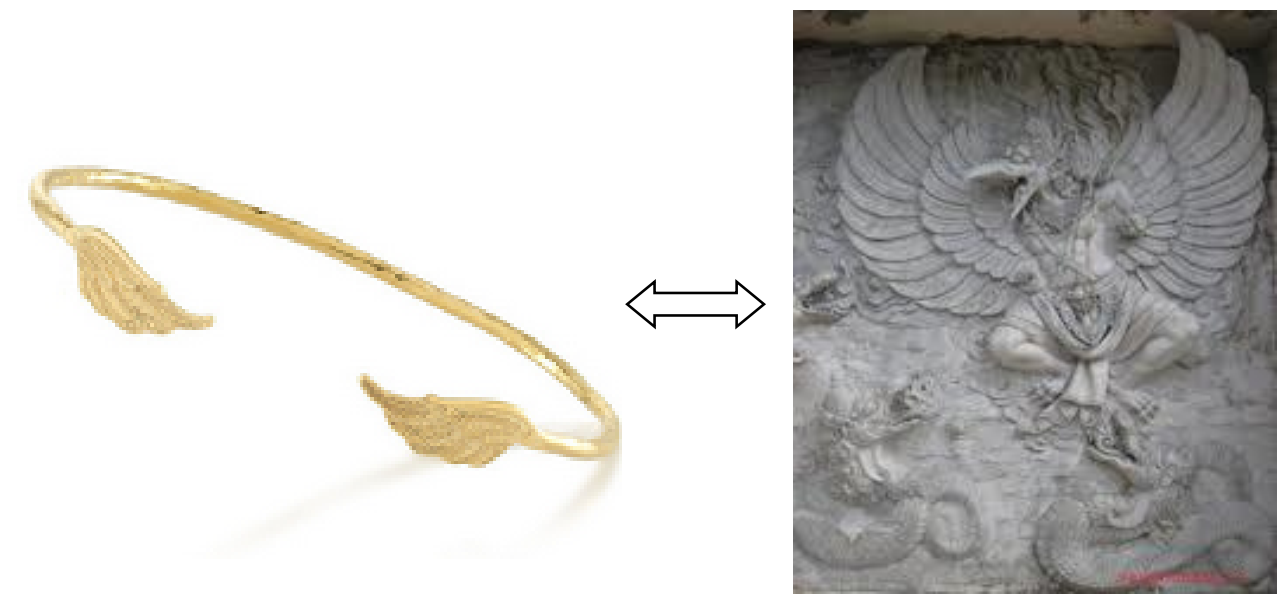

Gambar 5. Tolula Jewelry Design - Garuda Bangle Gold Dip (Sumber : www.shoptulola.com, 2015)

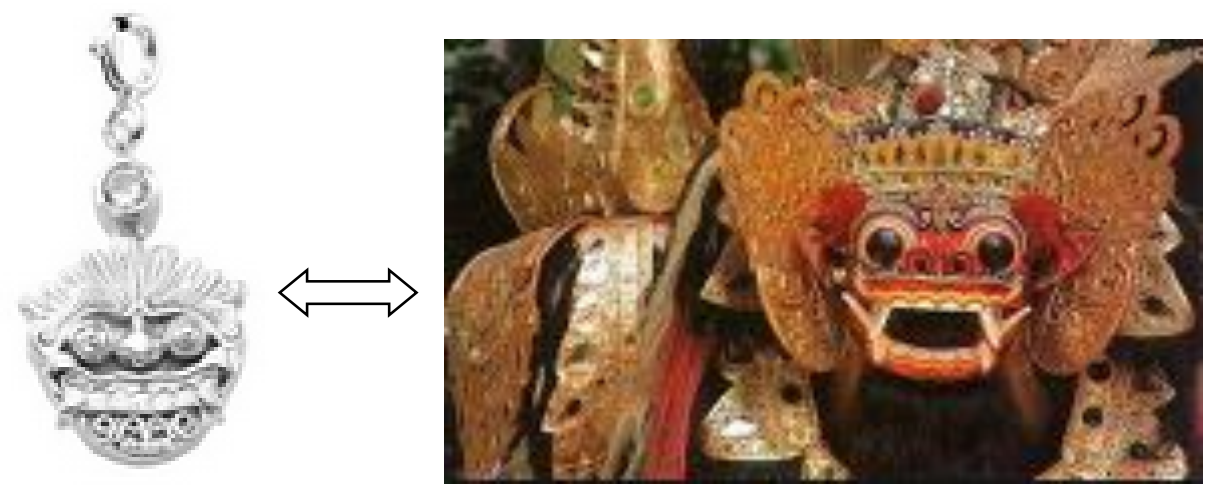

Gambar 6. Tolula Jewelry Design - Barong Charm Silver (Sumber : www.shoptulola.com, 2015)

para burung. Bahkan pada tradisi Bali sejak zaman dahulu kala, burung garuda ini dimuliakan sebagai tuan segala makhluk yang dapat terbang serta dimuliakan pula sebagai raja agung para burung.

Barong Bali adalah satu ragam seni pertunjukan Bali. Barong merupakan sebuah tarian tradisional Bali yang ditandai dengan topeng dan kostum badan yang dapat dikenakan oleh satu atau dua orang untuk menarikannya. Di Bali ada beberapa jenis barong yakni Barong Ket, Barong Bangkal, Barong Landung, Barong Macan, Barong Gajah,
Barong Asu, Barong Brutuk, Barong Lembu, Barong Kedingkling, Barong Kambing, dan Barong Gagombrangan. Barong Bali dipercaya sebagai metamorfosis dari barong ponorogo atau Reog, oleh raja Airlangga saat mengungsi ke pulau Bali untuk menyelamatkan diri. selain barong ponorogo yang dibawa ke bali, melainkan juga seperti seni sastra, aksara jawa, serta keagamaan.

Pura Besakih adalah tempat persembahyangan agama Hindu di Bali dan di dalam area Pura ini, tidak hanya terdapat satu Pura, tetapi banyak Pura. 
Karena begitu banyaknya terdapat Pura dalam satu wilayah, maka Pura Besakih Bali adalah Pura terbesar di Indonesia. Pura Besakih Bali juga sering disebut dengan nama Pura Agung Besakih. Lokasi Pura Besakih terdapat di Desa Besakih, Kecamatan Rendang, Kabupaten Karangasem, Bali. Pura Besakih di Bali merupakan pusat kegiatan keagamaan bagi umat Hindu Bali dan Pura Penataran Agung Besakih
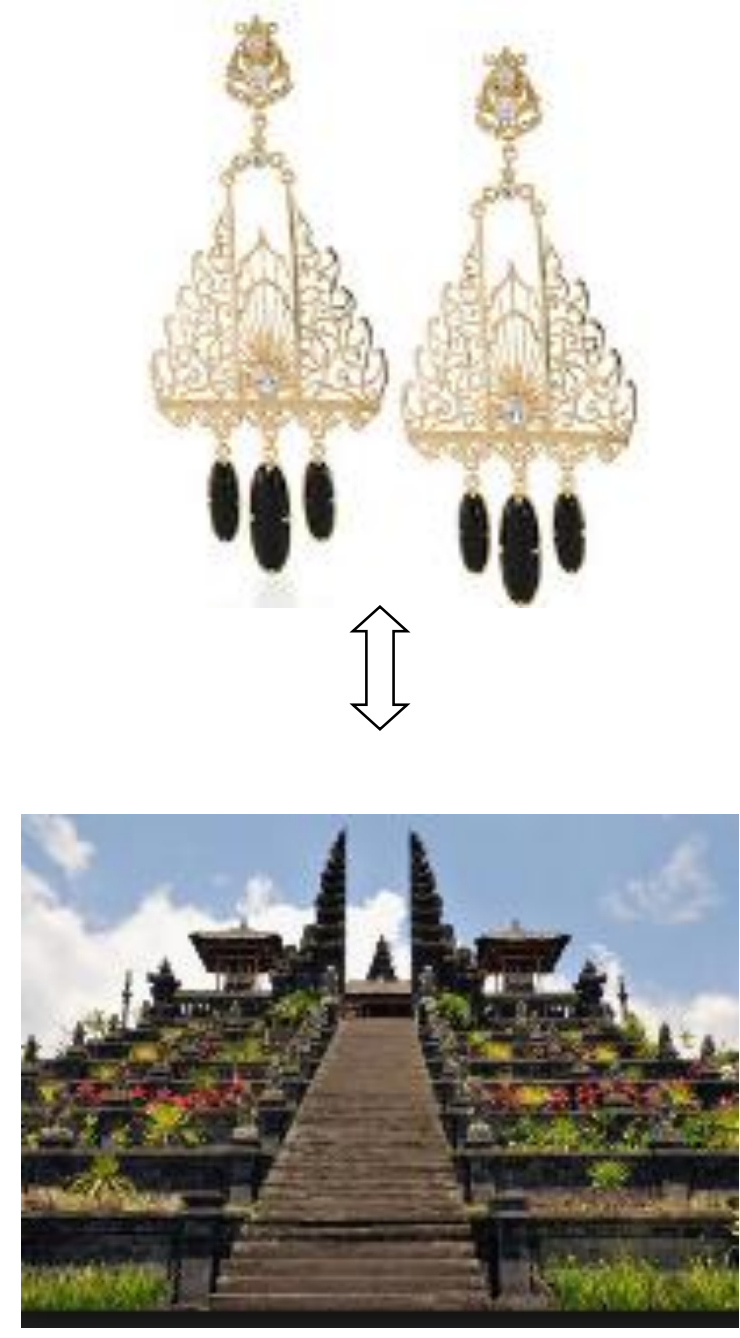

Gambar 7. Tolula Jewelry Design - Gateway to Besakih Earring (Sumber : www.shoptulola.com, 2015) adalah Pura terbesar di wilayah Pura ini. Pura Penataran Agung Besakih paling banyak memiliki bangunan untuk persembahyangan, orang Bali biasa sebut dengan nama Pelinggih dan merupakan pusat dari Pura ini.

\section{Analisa Desain Perhiasan Tulola Jewelry}

Desain perhiasan Tulola Jewelry didesain dengan memadukan unsurunsur motif tradisional Bali yang sudah ada sebelumnya, dengan menyerap unsur-unsur disain modern yang memiliki kekhasan tersendiri, sehingga bisa bersaing di pasaran, baik lokal, nasional, maupun internasional. Dalam menciptakan karya seni kerajinan yang berkualitas, penerapan elemen-elemen seni rupa seperti : garis, bidang, warna, tekstur, ruang, dan prinsipprinsip penyusunan seperti: komposisi, proporsi, kesatuan, kontras, irama, dan keseimbangan, sehingga muncul karya dengan rancangan disain yang inovatif.

Menurut Suarti dalam blognya di http://sobatbudaya.or.id, Berdasarkan penelitian yang dilakukan oleh Nyoman Ngidep Wiyasa :

- $\quad$ Ciri khas perhiasan di Bali terletak pada jejawan atau jawan, material perak berbentuk bola atau lempengan kecil. Ada dua jenis jawan, yaitu jawan pasir dan jawan plat (berbentuk lempengan). Jawan ditempa dan ditata dengan granulasi membentuk untaian tumbuhan, bentuk melingkar. 


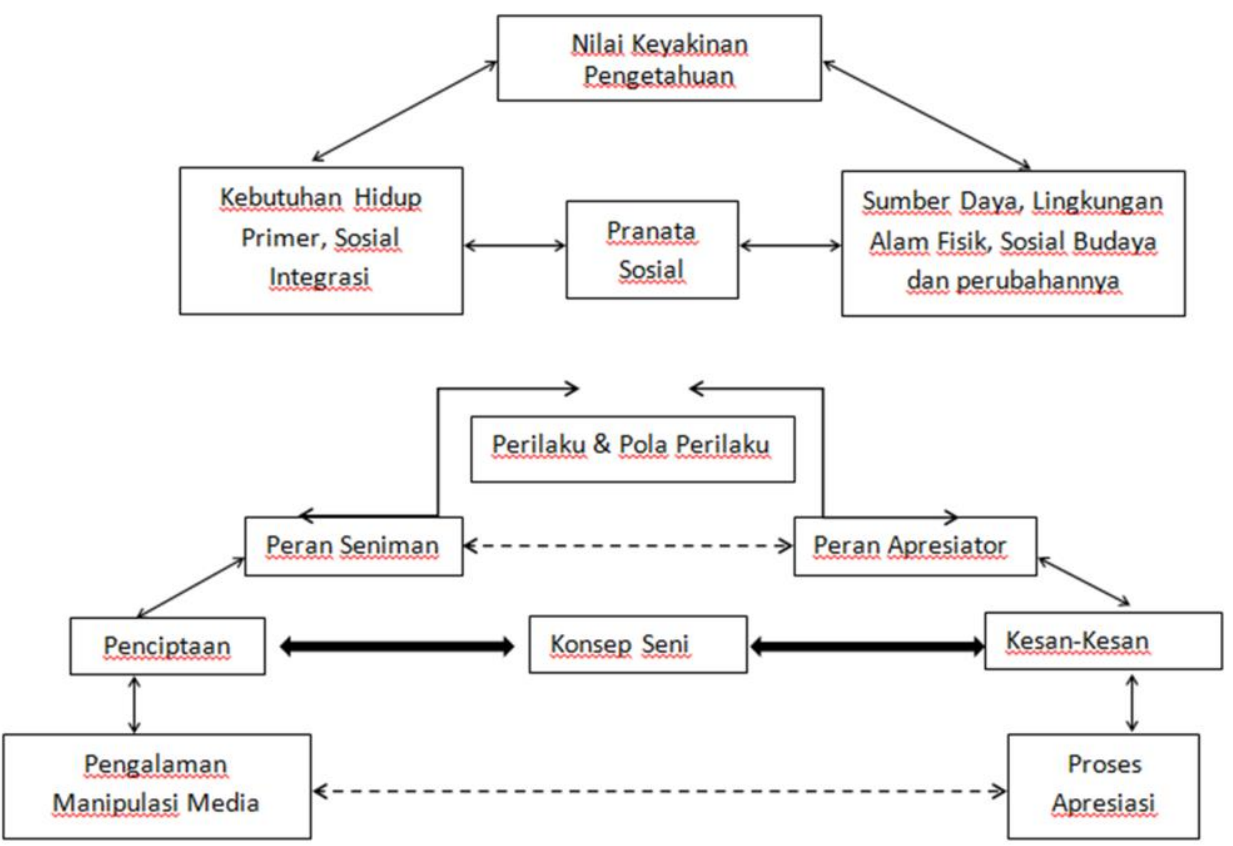

Gambar 8. Konstekstual interaktif karya (Sumber : Rohidi, Metode Penelitian Seni, 2011: 4)

- Filosofi Jawa terlihat dari material perak dan emas yang menyerupai titik-titik kemudian membentuk garis. Sebuah karya seni selalu mulai dari sebuah garis, begitupun dengan kehidupan manusia.

Berdasarkan analisis pemaparan diatas dapat dibuat Konsep Interaktif Karya Desain Perhiasan Tulola Jewelry, tampak dalam tabel gambar 8 .

Peran seniman, apresiator dan teknologi tercermin dalam konsep desain Tulola Jewelry, yang memasuki segmentasi pasar High-End Internasional. Dengan didukung oleh kecanggihan alat produksi sebagai komponen penyeimbang teknik dari seniman, penciptaan desain perhiasan tulola menghasilkan desain-desain yang mampu menarik konsumen lokal dan mancanegara.

Perilaku konsumen semakin beralih proses apresiasinya kepada sumbersumber online untuk membeli produkproduk sejenis. Pengaruh media yang kuat dengan tampilan desainberkarakter elegan klasik pada website, memberikan dampak persepsi lebih pada para konsumen Tulola Jewelry.

Pada website Tulola Jewelry tersebut merupakan penggunaan perhiasan yang dikenakan oleh perempuan Indonesia, dalam upaya dan strategi pemasaran Tulola mengemas perhiasan dengan beberapa style elegan klasik yang digunakan oleh para artis papan atas Indonesia diantaranya Ayu Dewi menggunakan Nusantara Necklace Gold Dip, Sarah Sechan menggunakan 

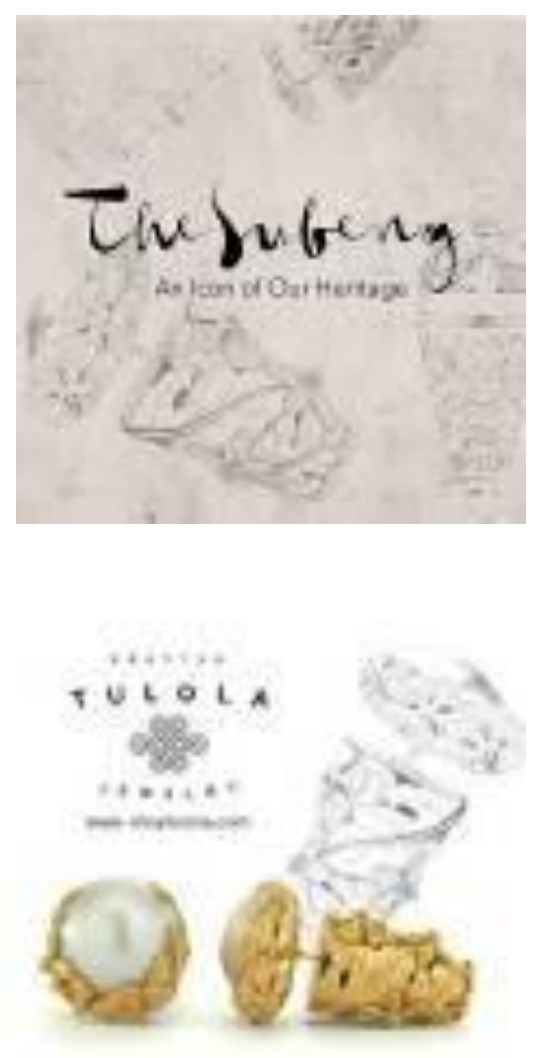

Gambar 9. Tulola Jewelry (Sumber : www.shoptulola.com, 2015)

subeng, Happy Salma menggunakan gelang berantai serta Wulan Guritno menggunakan Canang Subeng in Black Onyx. Tampilan website Tulola Jewelry mengusung konsep High-End Jewelry untuk pengguna perhiasan perempuan Indonesia khususnya, namun tidak tertutup kemungkinan dari pengguna perempuan di manca negara.

Subeng sendiri digunakan sebagai pelengkap perhiasan dalam tari pendet sebagai tarian ritual sakral di Bali. Karakteristik perhiasan Subeng ini antara lain:
- Bentuk Subeng Tulola tetap mencirikan bentuk klasik subeng,

- Penggunaan motif floral (dedaunan) dan bunga padma (teratai),

- Warna emas yang mewakili bentuk klasik serta penggunaan subeng untuk acara formal/seremonial,

- Penggunaan material mutiara dan emas untuk memberikan kesan luxurious, klasik dan elegan,

- Penggunaan teknik dalam pembuatan perhiasan Tulola adalah Custom Engraved (ukiran pada emas) dan Melting ( peleburan emas dan sterling silver / perak murni dan tembaga), terbuat dari $92,5 \%$ Perak Murni, dilapisi oleh emas 18K menggunakan Mutiara Air Tawar Bulat $15-16 \mathrm{~mm}$, panjang $32 \mathrm{~mm}$, diameter $17 \mathrm{~mm}$.

Perhiasan subeng setelah proses pendesainan ulang mengalami perubahan komposisi menjadi lebih ramping serta ukuran yang lebih ringan, sehingga dalam penggunaannya, subeng dapat dipakai sehari-hari (daily use) selain pada acara formal.

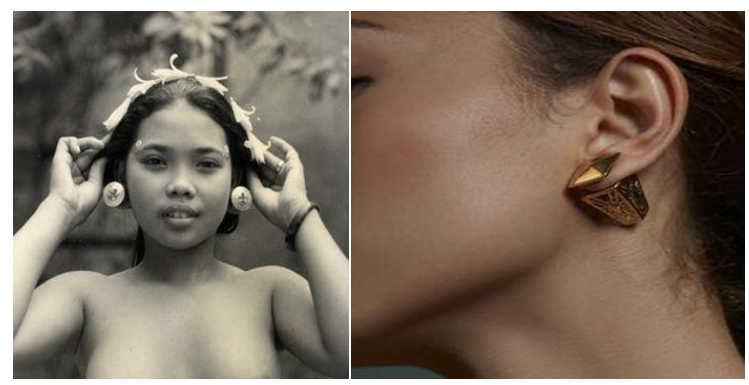

Gambar 10. Perubahan bentuk dan ukuran Subeng (Sumber : Rika Nugraha, 2015) 
Analisis pada Subeng Geometris meliputi, antara lain:

- Bentuk Subeng Geometris tetap mencirikan bentuk klasik subeng,

- Penggunaan motif floral (dedaunan) dan bunga padma (teratai) dengan komposisi geometris,

- Warna emas yang mewakili bentuk klasik serta penggunaan subeng untuk acara formal/seremonial,

- Penggunaan teknik dalam pembuatan perhiasan Subeng Geometris adalah filigree ( Benang emas ) dan melting ( peleburan emas dan sterling silver / perak murni dan tembaga), terbuat dari 92,5\% Perak Murni, dilapisi oleh emas 18K panjang $32 \mathrm{~mm}$, diameter $17 \mathrm{~mm}$.
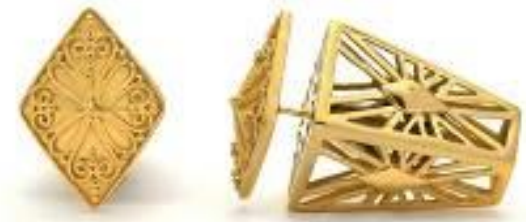

Gambar 11. Cosmic Geometry Subeng (Sumber:www.shoptulol a.com, 2015)

\section{KESIMPULAN}

Perkembangan perhiasan Indonesia secara personalisasi diharapkan dapat merubah pola pikir masyarakat lebih menghargai produk yang digunakannya. Keragaman budaya sebagai akar tradisi dapat terus dilestarikan dengan beragam salah satunya melalui eksistensi perhiasan Indonesia. Dalam hal ini perhiasan sebagai salah satu produk budaya digunakan sebagai sarana mediasi penyampaian pesan emosional dapat meminimalisir konsumsi produk berlebihan. Tulola Jewelry memiliki beberapa aspek dalam kajian ikonografi berhubungan dengan penerapan filosofi emotional design. Tinjauan aspek diantaranya berupa target pengguna dan studi karakter pengguna.

Karakter pengguna Tulola Jewelry adalah wanita urban dengan gaya hidup sebagai identitas sosial seseorang dalam kehidupan modern. Mulai dari cara berpakaian, produk belanjaan, gadget yang dipakai, hobi yang dijalani, tempat bersosialisasi, komunitas yang diikuti, dan sebagainya. Dalam menjalani tuntutan gaya hidup yang ada, manusia urban dituntut untuk mengkonsumsi produk yang terkadang tidak dibutuhkannya sehingga mengarah pada budaya konsumtif.

Studi bentuk Tulola Jewelry terinspirasi dari kebudayaan Bali, dengan mengolah ikon-ikon filosofi Bali yang memiliki nilai-nilai sakral dalam fungsinya. Pengolahan studi bentuk tidak merubah esensi dari dimensi wujud seni Bali tersebut. Bentuk desain Tulola Jewelry mengungkapkan lambang yang mengungkapkan emosi dan gagasan perhiasan dengan sentuhan mitos, sejarah, dan spirit khatulistiwa serta keindahan perorangan sebagi wujud ekspresi seni.

Studi material dalam setiap koleksi Tulola, perhiasan yang berbasis di Bali ini menggunakan berbagai jenis Kristal, 
Amethyst, Lemon Quartz, Mutiara, Berlian. Material utama menggunakan logam emas, sterling silver ( perak campuran), serta 92,5\% Perak murni dilapisi oleh Emas 18K dalam setiap pembuatannya. Sementara dalam hal teknik lebih kepada penggunaan teknik Custom engraved ( Ukiran pada Emas), Gold granulation ( Permukaan dihiasi butiran emas kecil), Filigree ( Benang perak) dan Melting (Peleburan).

\section{DAFTAR PUSTAKA}

Charlotte Mankey \& Phyllis Tortora 2003. Dictionary Of Fashion" Laurence King Publishing Ltd, Fairchild Publication, Inc
Hoeve, Van

1883. Ensiklopedi Nasional Indonesia"PT Ichtiar

Oka A, Yetty

1985. Komersialisasi Seni Dalam Pariwisata Bandung, PN Angkasa

Sachari, Agus

2004 Estetika Makna Simbol dan Daya"ITB, Bandung Strinati, Dominic.

1995 An Introduction to Theories Of Popular Culture" Terjemahan Abdul Mukhid, Bentang Budaya, Yogyakarta

Widagdo.

2005 Desain dan Kebudayaan".ITB, Bandung 